\title{
Management of patients with cervical spine trauma in the emergency department: a systematic critical appraisal of guidelines with a view to developing standardized strategies for clinical practice
}

\author{
Elisa Gesu ${ }^{1,2}$ (1) $\cdot$ Pietro Bellone ${ }^{1,2} \cdot$ Mattia Bonzi $^{2} \cdot$ Giulio Andrea Bertani ${ }^{3} \cdot$ Barbara Brignolo Ottolini $^{2} \cdot$ Paola Bosco $^{9}$. \\ Giorgio Conte ${ }^{4} \cdot$ Matteo Ferrari $^{5}$. Elisa Maria Fiorelli ${ }^{6} \cdot$ Hayato Kurihara $^{7} \cdot$ Monica Solbiati $^{1,2} \cdot$ Luigi Piero Solimeno $^{8}$. \\ Giorgio Costantino ${ }^{1,2}$
}

Received: 15 February 2021 / Accepted: 29 August 2021 / Published online: 5 October 2021

(C) The Author(s) 2021, corrected publication 2021

\begin{abstract}
Several guidelines on the evaluation of patients with suspected cervical spine trauma in the Emergency Department (ED) exist. High heterogeneity between different guidelines has been reported. Aim of this study was to find areas of agreement and disagreement between guidelines, to identify topics in which further research is needed and to provide an evidencebased cervical spine trauma algorithm for ED physicians. The three most relevant guidelines published on cervical spine trauma in the last 10 years were selected screening websites of the main scientific societies and through the comparison of a normalized Google Scholar and SCOPUS citation index. We compared the selected guidelines through seven a-priori defined questions. In case of disagreement between the guidelines or if the quality of evidence appeared low, evidence from published systematic reviews on the topic was added to build an evidence-based algorithm for approach to spinal trauma in the ED. The three selected guidelines were: NICE 2016, Eastern Association for the Surgery of Trauma 2009 and American Association of Neurological Surgeons and Congress of Neurological Surgeons 2013. We found complete agreement on one question, partial agreement for one questions, no agreement for two questions, while agreement was not assessable for 3 questions. The agreement between different guidelines and the evidence on which recommendations are based is low. An attempt to build an evidence-based algorithm has been made. More studies are needed on many topics.
\end{abstract}

Keywords Cervical spine $\cdot$ Cervical spine trauma $\cdot$ Emergency Department $\cdot$ Guidelines

Elisa Gesu and Pietro Bellone contributed equally to this manuscript.

Elisa Gesu

elisa.gesu@unimi.it

1 Università degli Studi di Milano, Milan, Italy

2 Emergency Department and Emergency Medicine, Fondazione IRCCS Ca' Granda Ospedale Maggiore Policlinico, Milan, Italy

3 Neurosurgery, Fondazione IRCCS Ca' Granda Ospedale Maggiore Policlinico, Milan, Italy

4 Neuroradiology, Fondazione IRCCS Ca' Granda Ospedale Maggiore Policlinico, Milan, Italy

5 Medical Direction, Fondazione IRCCS Ca' Granda Ospedale Maggiore Policlinico, Milan, Italy
6 Internal Medicine Allergology and Immunology, Fondazione IRCCS Ca' Granda Ospedale Maggiore Policlinico, Milan, Italy

7 Emergency Surgery and Trauma Unit, IRCCS Humanitas Research Hospital, Rozzano, Milan, Italy

8 Orthopedics and Traumatology, Fondazione IRCCS Ca' Granda Ospedale Maggiore Policlinico, Milan, Italy

9 Health Professions Direction, Fondazione IRCCS Ca' Granda Ospedale Maggiore Policlinico, Milan, Italy 


\section{Introduction}

Trauma is one of the main reasons for patient assessment in emergency departments. Many patients with trauma are suspected of having lesions of the cervical spine [1]. The evaluation and management of patients with cervical spine trauma can be problematic because, on the one hand, missing cervical spine injury (CSI) can have dramatic consequences, and on the other hand, starting an inappropriate diagnostic pathway can be the cause of unnecessary radiation exposure, prolonged emergency department (ED) stay (with the related complications [2] and risk of overcrowding), and over-diagnosis.

Guidelines should help physicians to take decisions that are evidence-based, appropriate and with an explicit evaluation of the risk-benefit ratio. However, guidelines have been deeply criticized. Previous studies have shown that many guidelines are not evidence-based and can be influenced by conflicts of interest. Furthermore, there is often no consensus on the evaluation of the evidence and the suggested recommendations among the various guidelines [3]. The contradictions in guideline recommendations can paradoxically increase the uncertainty of the busy physician.

The aim of this paper was to systematically compare the most important guidelines on cervical spine trauma, to find areas of agreement and disagreement between guidelines, to identify topics in which further research is needed and to provide an evidence-based algorithm with which to approach patients with cervical trauma in the ED.

\section{Methods}

This study is a systematic comparison of secondary evidence.

Briefly, we initially screened the websites of the main medical scientific society interested on the topic, searching for proposed guidelines. Then, a systematic search of the all the available guidelines on cervical spine trauma published in literature was performed, screening the PubMed database for key terms referring to guidelines on this topic and choosing the most cited. We lastly asked to experts and looked the references to find further guidelines.

We decided in advance to select up to a maximum of three guidelines for comparison.

Moreover, a search of literature was performed to find any systematic review and metaanlysis on spinal trauma.

The guidelines were selected and compared in terms of seven a-priori emergency department questions. The concordance between different guidelines was evaluated and, in case of discrepancy, the presence of published systematic reviews on the topic was verified in order to find more evidence on the topic. Finally, an algorithm for the management of these patients in the ED was proposed, emphasizing the quality of evidence and the strength of recommendations.

\section{Guidelines search and selection strategy}

We initially searched and included guidelines on the websites of medical scientific societies related to the topic. In particular, we screened the National Institute for Health and Care Excellence (NICE) website, the American College of Physicians (ACP) website, the American College of Emergency Physicians (ACEP) website to include in our study any guideline on cervical spine trauma.

We decided in advance to select up to a maximum of three guidelines for comparison, the number of three has been a-priori chosen to equilibrate the possibility of comparison among them and to permit the readability of the manuscript. Such number has been previously adopted by similar studies [3].

We also decided in advance to perform a guideline search in literature in case of less than three guidelines on the topic were found on medical societies' websites.

In such case, we then searched the PubMed database to find any other guideline on the topic published in the past 10 years. In case of multiple versions of the same guideline, the most recent was considered.

A systematic search of the literature was performed, screening MEDLINE database for the following terms:

(((((spine)

AND

((injury) OR trauma)))

AND

((guideline*) OR guidelines)))

OR

(((spine)

AND

((injury) OR trauma))

AND

Practice Guideline[ptyp]).

Among the results, we included the most cited guidelines in order to reach the number of three guidelines selected for comparison. To compare the citations between guidelines we analysed the guidelines citations on Google Scholar and SCOPUS. We normalized the total number of citations based on the year of publication (number of citations on SCOPUS and Google Scholar divided by the difference between the year of the literature search and year of publication). This method has been previously adopted by similar studies [3].

We lastly asked to experts and looked at references of studies to find any additional relevant guideline.

Two different researchers (EG and PB) independently screened all titles and abstracts. In case of disagreement, a 
consensus was reached through the consultation of a third researcher (GC).

Last guidelines search was performed in January 2021.

\section{Literature search}

A search aimed to find systematic review and metanalyses on cervical spine trauma was performed, entering in $P u b$ Med the following keywords "(spine) AND ((injury) OR (trauma))", filtering results by "systematic reviews" and "metanalysis.

\section{A-priori questions}

Seven questions, thought to be the most clinically relevant on the topic, were pre-defined as follows: (1) Which patients should be evaluated for traumatic cervical injury? (2) Who should not have cervical spine imaging performed? (3) Who should undergo cervical spine imaging? (4) Which kind of imaging should be performed as an initial investigation? (5) How many and which segments of the cervical spine need to be investigated? (6) Within what timeframe should the imaging report be received? (7) When should the cervical collar be removed?

\section{Data collection}

Two reviewers (PB and EG) independently extracted from the guideline data regarding article title, journal, year of publication, first author, medical society, search strategy, setting of guidelines' applications, system used to grade the guidelines' recommendations and the reported references. The answer for each question and the quality of evidence/ level of recommendation, according to the method used by the guideline, was extrapolated — if possible — for each stated point.

\section{Guideline evaluation}

Differences and similarities between the selected guidelines were evaluated. Agreement between the guidelines was defined as follows: (1) no agreement when the guidelines stated different recommendations; (2) agreement when the guidelines suggested the same diagnostic measures or a similar patients' management strategy; (3) partial agreement when different guidelines agreed, with some differences; (4) not available when at least one of the guidelines did not address the topic.

In order to facilitate the comparison between the guidelines, the quality of evidence and the strength of recommendation declared from every guideline for each recommendation were extrapolated, if possible, and expressed through the GRADE (Grading of Recommendations, Assessment,
Development and Evaluations) system, considering what was expressed by the guidelines' authors and briefly reevaluating the references.

If the GRADE system was already used to rank the evidence by the authors, we confirmed their statement.

Briefly, the GRADE system allows grading of the quality of evidence and strength of recommendations. It has the advantages of providing a clear separation between judging confidence in the estimated effect and strength of recommendations and providing a clear, pragmatic interpretation of strong versus weak recommendations. Therefore, unlike many other grading systems, the GRADE approach emphasizes that the strength of a recommendation is affected by factors other than quality of evidence (i.e. values and preferences, costs) [4, 5].

Two different reviewers (PB, EG) independently assessed agreement between guidelines. In case of discrepancy between the two reviewers, a consensus was reached with the contribution of a third reviewer (GC).

In case of agreement between guidelines we provided a pooled rating of recommendations using the GRADE system (see Tables 3 and 4 in the Appendix).

\section{Literature review and identification of topics for future research}

In case of disagreement between the guidelines or if the quality of evidence appeared to be low, we searched for more evidence in systematic reviews on the issue. In case of lacking evidence, we underlined topics needing future research.

\section{Algorithm development}

Starting from the agreement between different guidelines and the evidence from the systematic reviews, using a modified GRADE grading evaluation system, we tried to develop an evidence-based algorithm for the management of cervical spine trauma patients in the ED.

\section{Results}

The medical societies' websites screening identified only the NICE guideline-entitled "Spinal injury: assessment and initial management" [6] — for inclusion in our study.

The literature search led to 1677 results. After reading titles and abstracts, 1672 were excluded, leaving 5 relevant papers $[7,8,16-18]$. Among these, the two most-cited in the past 10 years $[7,8]$ were chosen: "Practice Management Guidelines for Identification of Cervical Spine Injuries Following Trauma: Update From the Eastern Association for the Surgery of Trauma Practice Management Guidelines Committee" and "Guidelines for the management of acute 
cervical spine and spinal cord injuries: 2013 update". Figure 1 shows the flow chart for study inclusion. Table 1 shows normalized citations for each guideline.

The literature screening filtered by systematic reviews and metanalyses led to 1.166 results. Among these, we found relevant in order to add more evidence to our comparison nine studies [1, 2, 9-16].

Fig. 1 Guidelines selection

Table 1 Normalized citations for each guideline

\section{Description of the guidelines}

Appendix Table 3 shows the main information about the selected guidelines

\section{Year of publication and setting}

The NICE guidelines were published in 2016. The Eastern Association for the Surgery of Trauma (EAST) Practice Management Guidelines were published in 2009 as an update to the previous EAST guidelines, published in 1998

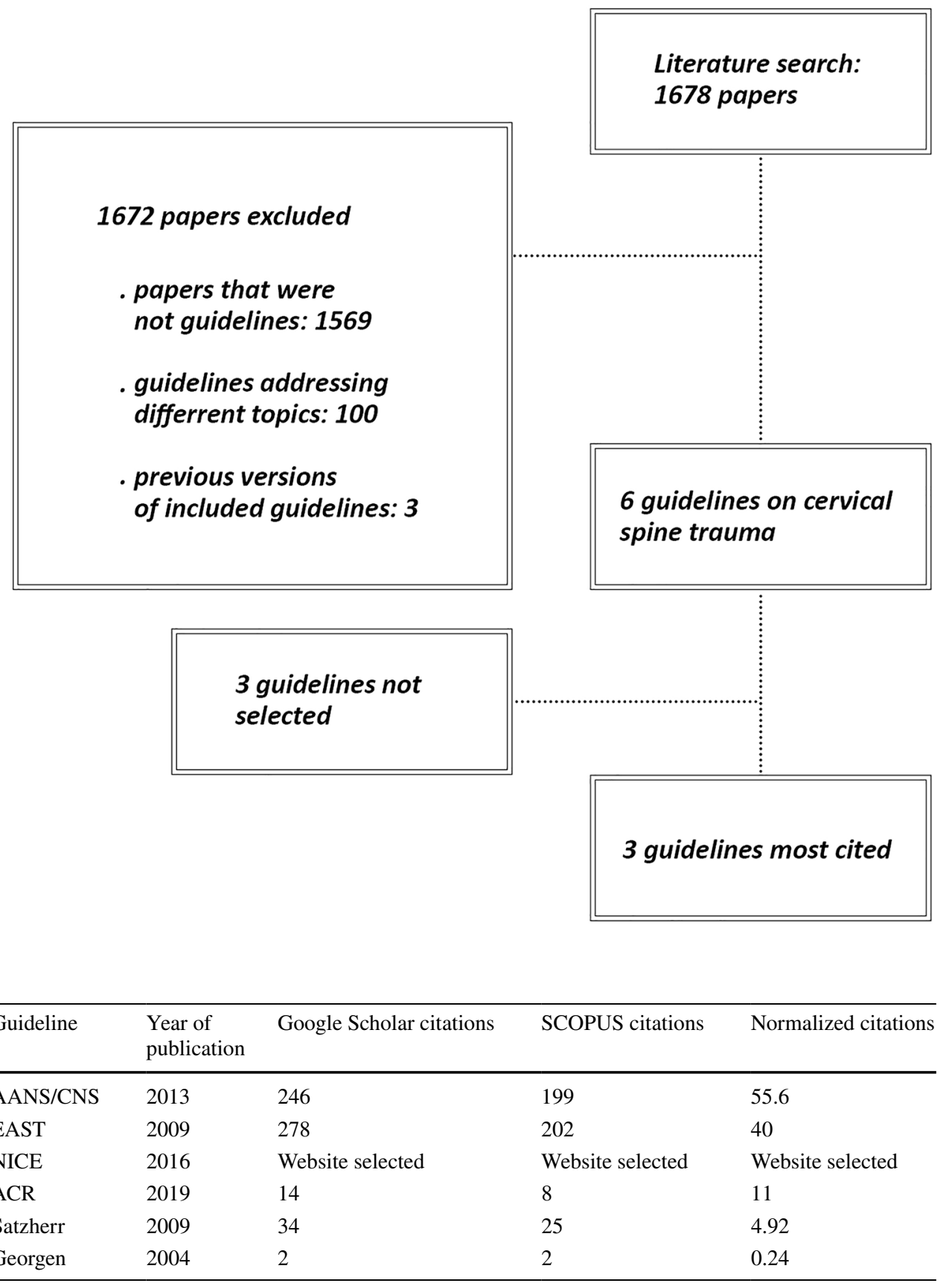


and 2000. The American Association of Neurological Surgeons and Congress of Neurological Surgeons (AANS/CNS) guidelines were published in 2013 and are an update to the original guideline of 2002. All three guidelines were developed for the ED setting.

\section{Grading recommendation system}

In the NICE guidelines, the evidence for outcomes from the included studies was evaluated and presented using an adaptation of the GRADE toolbox developed by the international GRADE working group [5].

In the EAST guidelines, articles were classified as Class I, II, or III, as described in the EAST primer on evidence-based medicine: Class I: Prospective, randomized clinical trials; Class II: Clinical studies in which data were collected prospectively or retrospective analyses based on clearly reliable data; Class III: Studies based on retrospectively collected data. The guideline recommendations were then classified as Level 1 (the recommendation is convincingly justifiable based on the available scientific information alone. This recommendation is usually based on Class I data; however, strong Class II evidence may form the basis for a level 1 recommendation); Level 2 (the recommendation is reasonably justifiable by available scientific evidence and strongly supported by expert opinion. This recommendation is usually supported by Class II data or a preponderance of Class III evidence); Level 3 (the recommendation is supported by available data but adequate scientific evidence is lacking. This recommendation is generally supported by Class III data).

In the AANS/CNS, the quality of evidence was assessed as Class I (well-designed and well-executed randomized controlled trials); Class II (comparative studies, including randomized controlled trials with significant flaws, nonrandomized cohort studies, or case-control studies), and Class III (case series and expert opinion). The strength of recommendations is classified as Level I, Level II and Level III.

\section{Answers and recommendations}

Considering all the seven questions, we found some recommendations for all the items. Complete agreement was found only for 1 question. For 3 question agreement was not assessable, while there was no agreement on 2 questions and partial agreement on 1 question. Overall, most of the recommendations were judged as strong through the GRADE system, although mainly founded on low quality of evidence (see Tables 4 and 5 in Appendix).

\section{Question 1. Which patients should be evaluated for traumatic cervical injury?}

\section{Comparison between guidelines}

Agreement between the three guidelines was not assessable because only one of the reviewed guidelines (NICE) answers this question, suggesting that all adults who present with suspected spinal column or spinal cord injury secondary to a traumatic event should be evaluated for traumatic cervical injury. Neither the strength of recommendation, the quality of evidence on which this recommendation is based nor the references were clearly reported in the guideline for this indication.

\section{Literature search and fields for future research}

Guidelines do not provide a definition of cervical spine trauma. A traumatic event involves multiple variables, which cannot be standardized under a specific definition. Therefore, the clinician should define whether an event can be considered relevant and harmful to the patient. It is unlikely that future studies could evaluate which kinds of patient should be screened for traumatic cervical spine lesions.

\section{Considerations}

It would be reasonable to state that every trauma patient, with the exception of minor isolated limb lesions, should be clinically evaluated for cervical injuries. It could be assumed that any patient suspected of having cervical spine trauma is eligible for cervical injury screening, from trivial to highenergy traumas. The selection of patients eligible for evaluation for cervical spine trauma remains a decision for the clinician.

\section{Question 2. Who should not have cervical spine imaging performed?}

\section{Comparison between guidelines}

All the reviewed guidelines answer this question, but there is no agreement between the three guidelines. Two guidelines (EAST, AANS/CNS) agreed in recommending not to perform imaging in the awake, alert, asymptomatic patient without neurological deficit, without neck pain or tenderness, without distracting injury, who is able to complete a functional range of motion examination. The EAST and the AANS/CNS guidelines refer to the NEXUS (National Emergency X-radiography Utilization Study) algorithm [9] plus evaluation of the cervical range of motion. In contrast, 
the NICE guidelines require that the Canadian C-spine rule (CCR) be met [10] (Table 2). These two approaches are hardly comparable from a methodological point of view because, while the EAST and the AANS/CNS guidelines use a list of criteria that must all be met, the CCR to which the NICE guidelines refer represents an algorithm with a series of consequential steps which must be progressively respected.

All the guidelines define the strategies on this topic as a strong recommendation. However, the NICE guidelines state that the recommendation is based on very low to low-quality of evidence, EAST guidelines are based on low quality of evidence, while the level of evidence is not assessable in the AANS/CNS guidelines. Of the three guidelines, only the EAST clearly states the references on which the recommendations are based.

\section{Literature search and fields for future research}

Several rules have been proposed for the screening of patients who present in the ED with cervical spine trauma and identification of those who really require imaging investigations. The NEXUS and CCR, the two most important rules on this topic, were published in 2000 and 2001 [9, 10]. The NICE guideline refers to the CCR for the management of patients with cervical spine trauma, while the EAST and the AANS/CNS guidelines use criteria similar to NEXUS. Although there are no extensive validation studies on these rules, the studies upon which they were established enrolled an extremely high number of patients and showed very encouraging results, which has frequently led to their use as a screening tool. However, the two protocols enrolled populations with different characteristics, had different study designs and proposed different approaches. NEXUS was a retrospective study that enrolled all the patients with suspected cervical spine trauma that underwent cervical X-ray by decision of the clinician. The CCR was a prospective study that had several exclusion criteria (in particular, it was not applicable to patients under 18 years) and had strict criteria to identify high-risk patients (in particular, mandatory imaging in patients over 65 years) (Table 2). Both used X-ray as the reference standard to identify cervical spine lesion, while different studies show that computed tomography (CT) has higher diagnostic accuracy and it is now considered the reference standard. In the literature, few validation and comparison studies of the two rules are available [11-14]. The CCR seems to be more accurate than the NEXUS and clinical judgment [15], but further studies are needed.

\section{Considerations}

There is not enough evidence to identify a single rule to be applied for patients with cervical spine trauma.
However, we suggest consideration of CCR in addition to clinical judgement to identify which patients with cervical spine trauma should undergo CT scan. Further validation studies on this topic would be useful.

Table 2

\section{Question 3. Who should undergo cervical spine imaging?}

\section{Comparison between guidelines}

All the reviewed guidelines answer this question, but there is no agreement between the three guidelines. For this query, between two guidelines (EAST and AANS/CNS) there is substantial agreement recommending imaging in all patients considered difficult to evaluate (obtunded, altered mental status) or symptomatic (the EAST guideline specifies patients with neck pain or tenderness and/or neurological deficit). One guideline (EAST) also recommends imaging in patients with distracting injury. The NICE guideline recommends imaging in all patients with GCS $<15$, or at high risk for cervical spine injury according to the CCR or patients at low risk for cervical spine injury according to the CCR but unable to actively rotate their neck 45 degrees left and right. All the guidelines define the strategies on this topic as strong a recommendation. However, the NICE guidelines declare that the recommendation is based on very low to low quality of evidence; the EAST guideline is based on low quality evidence, while the level of evidence is not assessable in the AANS/CNS guideline. None of the three guidelines clearly state the references on which the recommendations are based.

\section{Literature search and fields for future research}

This answer is similar to the previous one. The NICE guidelines set 65 years of age as the cut-off for performing the diagnostic test. Setting an age cut-off could be problematic. While it is reasonable to assume that older age is related to higher risk, further studies should be performed to evaluate the increase in risk of cervical spine injury with age and to assess whether using different age thresholds could be feasible and useful.

\section{Considerations}

Considering that an ideal rule is not available, it could be considered reasonable to perform a $\mathrm{CT}$ scan in patients younger than 65 years at high risk, considering CCR and clinical judgment, in polytraumatized patients, in patients older than 65 years that had a cervical spine trauma considered not to be trivial based on clinical judgement (even if asymptomatic).

This suggestion should be considered based on low-quality evidence and future studies are needed to evaluate this topic. 


\section{Question 4. Which kind of imaging should be performed as an initial investigation?}

\section{Comparison between guidelines}

All the reviewed guidelines answer this question and there is agreement between the three guidelines. All the reviewed guidelines agree recommending CT scan as the first-choice imaging investigation for cervical spine trauma, because of the better sensitivity if compared with X-ray imaging. The AANS/ CNS guideline also specifies that if high-quality CT imaging is not available, a 3- view cervical spine series (anteroposterior, lateral, and odontoid views) is recommended. This should be supplemented with CT (when available) if necessary.

All the guidelines define the strategies on this topic as a strong recommendation. However, the NICE guideline states that the recommendation is based on very low to low quality of evidence; the EAST guidelines are based on low quality of evidence, while the level of evidence is not assessable in the AANS/CNS guideline. Of the three guidelines, only the EAST clearly states the references on which the recommendations are based.

Table 2 NEXUS rule (used by EAST and AANS/CNS guidelines) vs Canadian C-spine rule (used By NICE guideline)

\begin{tabular}{ll}
\hline EAST and AANS/CNS guidelines & NICE guidelines (Canadian C-spine rule) \\
\hline Normal level of alertness & $\begin{array}{l}\text { 1. High-risk factors that mandates radiography? } \rightarrow \text { If } \\
\text { YES perform imaging }\end{array}$
\end{tabular}

\section{Asymptomatic}

Absence of a focal neurologic deficit

Absence of neck pain tenderness at the posterior midline of the cervical spine

No evidence of intoxication

Absence of clinically apparent pain that might distract the patient from the pain of a cervical-spine injury

Able to complete a functional range of motion Examination
Age $\geq 65$ years or

Dangerous mechanism $^{1}$ or

Paresthesias in extremities

If $\mathrm{NO} \rightarrow$ following step

2. Low-risk factors that allows safe assessment of range of motion? $\rightarrow$ If $\mathrm{NO}$ perform imaging

Simple rear-end $\mathrm{MVC}^{2}$ or

Sitting position in ED or

Ambulatory at any time or

Delayed onset of neck pain ${ }^{3}$ or

Absence of midline C-spine tenderness

If YES $\rightarrow$ following step

$\downarrow$

3. Able to actively rotate neck $45^{\circ}$ left and right? $\rightarrow$

if YES $\rightarrow$ no imaging, remove cervical collar

If $\mathrm{NO} \rightarrow$ perform imaging

${ }^{1}$ Dangerous mechanism:

Fall from $\geq 1 \mathrm{~m} / 5$ stairs

Axial load to head, e.g. diving

MVC at high speed ( $>100 \mathrm{~km} / \mathrm{h})$, or with rollover or ejection

Motorized recreational vehicle

Bicycle collision

${ }^{2}$ Simple rear-end MVC excludes:

Pushed into oncoming traffic

Hit by bus/large truck

Rollover

Hit by high-speed vehicle

${ }^{3}$ Delayed

Not immediate onset of neck pain

Exclusion criteria

Patients younger than 16 years; minor injuries, such as simple lacerations, and no suspicion of cervical spine trauma; GCS score $<15$; grossly abnormal vital signs; injured more than $48 \mathrm{~h}$ previously; penetrating trauma; acute paralysis; known vertebral disease (ankylosing spondylitis, rheumatoid arthritis, spinal stenosis, or previous cervical surgery; patients returned for reassessment of the same injury; pregnancy. 


\section{Literature search and fields for future research}

Holmes' meta-analysis showed that CT has better sensitivity than X-ray in patients at high risk (pooled sensitivity of radiography versus $\mathrm{CT}$ as 52 percent and 98 percent, respectively [10]). However, it is important to consider which kind of cervical spine lesion could be missed with radiography. Improvement in diagnostic accuracy does not mean improvement in management and outcome for the patient. Even if the segments less evaluable with radiography are those most involved in CSI, it is possible that better sensitivity in diagnosing cervical spine lesions could result in increasing the detection of non-clinically relevant lesions, with no benefit for the patient.

Moreover, the cervical spine rules, on which we have already commented, are based on radiography as the reference standard, and we do not know if replacing radiography with CT could be useful. In conclusion, more studies are needed on the comparison between radiography and spinal CT, setting patient outcomes as the reference standard rather than an abnormality found in the imaging.

\section{Considerations}

Considering the evidence available in the literature, if imaging is considered necessary, CT scan should be performed.

This suggestion should be considered based on low quality evidence.

\section{Question 5. How many and which segments of the cervical spine need to be investigated?}

\section{Comparison between guidelines}

Agreement between the three guidelines is not assessable because two of the reviewed guidelines (NICE and AANS/ CNS) do not answer this question. The EAST guideline recommends imaging from the occiput to T1. This strategy is defined as a strong recommendation based on low quality of evidence. The references on which the recommendations are based are not clearly stated.

\section{Literature search and fields for future research}

Based on the literature, the most common sites of injury are the second cervical vertebra $(\mathrm{C} 2$, or axis, 33\%) and the region of the three vertebrae C5, C6, and C7 (50\%) [11, 12]. The level of the cervical spine lesion correlates to the severity of the outcome (the higher the lesion, the worse the outcome, from death to quadriplegia, paraplegia or other disabling conditions) [1]. These sites are the most difficult to evaluate with X-ray $[15,16]$.

\section{Considerations}

If imaging of the cervical spine is necessary, investigation from the occiput to T1 should be performed. This suggestion is based on high-quality evidence and should be considered as a strong recommendation.

\section{Question 6. Within what timeframe should the imaging report be received?}

\section{Comparison between guidelines}

Agreement between the three guidelines is not assessable because only the NICE guideline answers this question, recommending that images should be interpreted immediately by a healthcare professional with training and skills in this area. This strategy is defined as a strong recommendation based on very low to low quality of evidence. The references on which the recommendations are based are not clearly stated.

\section{Literature search and fields for future research}

From a clinical point of view, maintaining a cervical collar is associated with negative side effects (risk of decubitus ulcer, worse ventilation) and discomfort for the patient [2]; moreover, a delay in the diagnosis of a severe cervical spine fracture could be associated with worsening of the prognosis. For these reasons, it is desirable that the imaging report be available as soon as possible. No study could address this type of question, and the answer should be based on the opinion of the experts and the hospital organization.

\section{Considerations}

A CT report should be obtained as soon as possible (ideally within one hour). This suggestion is based on lowquality evidence and should be considered as a weak recommendation.

\section{Question 7. When should the cervical collar be removed?}

\section{Comparison between guidelines}

All the reviewed guidelines answer this question and there is partial agreement between the three guidelines. Two guidelines (EAST and AANS/CNS) agree in recommending to remove the cervical collar in the awake, alert, asymptomatic patient without neurological deficit, without neck pain or tenderness, without distracting injury, who is able to 
complete a functional range of motion examination. These two guidelines agree even in recommending to consider continuing cervical immobilization until the patient is asymptomatic or to remove the cervical collar after a negative MRI or after adequate flexion-extension X-ray, in the awake, symptomatic patient with a negative CT scan. Moreover, the AANS/CNS guideline suggests possibly discontinuing cervical immobilization at the discretion of the treating physician. Only one guideline (EAST) considers the obtunded patient with a negative CT scan and gross motor function of all four extremities, recommending to continue cervical collar immobilization until a clinical examination can be performed or to remove the cervical collar on the basis of CT alone or plus MRI and, if MRI shows nothing abnormal, to remove the cervical collar. The NICE guidelines require patients to have low- risk factors for cervical spine injury as identified and indicated by the CCR, to be pain free and able

to actively rotate the neck 45 degrees left and right. The strength of the recommendations and quality of evidence on which these are based are shown in Table 1 .

\section{Literature search and fields for future research}

It is safe to remove the cervical collar if the patient is asymptomatic and the imaging examination is negative. The literature is not clear about which management strategy could be the best in patients who are still symptomatic but have negative imaging.

\section{Considerations}

In clinical practice, the cervical collar can probably be safely removed in asymptomatic patients and in patients who are clinically evaluable, with have no neurological deficits and with negative CT imaging. In special situations the clinician should evaluate case-by-case if maintaining cervical collar and/or perform more investigations. In doubtful situations, spine specialist consultation may be considered. This suggestion is based on low-quality evidence and should be considered as a weak recommendation.

\section{Discussion}

The aim of this paper was to compare the main guidelines in the literature on cervical spine trauma evaluation and management, to identify topics in which further research is needed, to extrapolate recommendations on several topics of interest and to provide, if possible, a univocal pathway that can help clinicians in approaching patients with suspected cervical trauma/injury. Evaluating the answers to our a-priori questions in the selected guidelines, it emerged that there was very scarce agreement between different guidelines. In particular, for only one question ("which kind of imaging should be performed as an initial investigation?", question 4) there was complete agreement in the answer. For one other question there was only partial agreement, for two questions there was no agreement, while for three questions it was not possible to establish any agreement because some guidelines did not cover the topic. This underlines that between the different guidelines there is wide inhomogeneity, not only between what is recommended but also in the covered topics. This fact could perhaps be explained by the fact that even when the same question is answered, the cited references often differ or, if the references are similar, the grade of recommendation can differ. Moreover, most of the recommendations are judged to be of low quality.

The guidelines use different criteria to evaluate the quality of evidence (QoL) and to state the strength of recommendation. In particular, the NICE guidelines state that they used the GRADE method, while the other two use their own tailored criteria. The GRADE, among those currently available, is a codified and reproducible evaluation system for the quality of the evidence and strength of the recommendations, but was published in 2013, after the AANS/CNS and the EAST guidelines.

The inhomogeneity between the grading system for QoL and strength of recommendations could represent an obstacle for the clinician examining several different guidelines and needing to identify the most useful one.

The analysis of the guidelines and the subsequent search of the available literature highlight that further studies are needed for multiple fields of research. In particular, more studies would be useful for the following: (1) comparing the available tools to screen high-risk patients for cervical spine injury with the purpose of identifying the most accurate one and definitively validating it, setting CT scan as the reference standard; (2) evaluating the increase in risk of cervical spine injury with age and the utility of different age thresholds; (3) comparing the diagnostic accuracy of spinal CT and $\mathrm{X}$-ray, setting some fixed outcome (based on the impact on the patient, i.e. need for surgery) as the reference standard; (4) evaluating the best management for patients who are still symptomatic after negative imaging.

We ultimately proposed an evidence-based algorithm for the management of patients with cervical spine trauma.

This study has several limitations. Our comparison approached only three guidelines - the most cited—which were published in different years with a time interval of 9 years between the oldest and the newest.

We selected the three most-cited guidelines, but these criteria do not necessarily guarantee that the suggested recommendations are the best available.

Our protocol is an attempt to help the clinician based on these guidelines, the available evidence-based information 
and our clinical experience and should be validated in the future.

\section{Conclusions}

There is scarce agreement between the guidelines addressing cervical spine trauma in the ED. Further research is needed to evaluate the best management of these patients and to identify patients that need to undergo specific diagnostic evaluation. Based on our comparison of the guidelines and literature search, we have proposed an evidence-based algorithm for the management of cervical spine trauma patients in the $\mathrm{ED}$ (Fig. 2).

\section{Appendix}

See Tables 3, 4 and 5.

COR: class of recommendation

LOE: level of evidence
Fig. 2 Proposed algorithm for management of patients suspected for cervical spine trauma

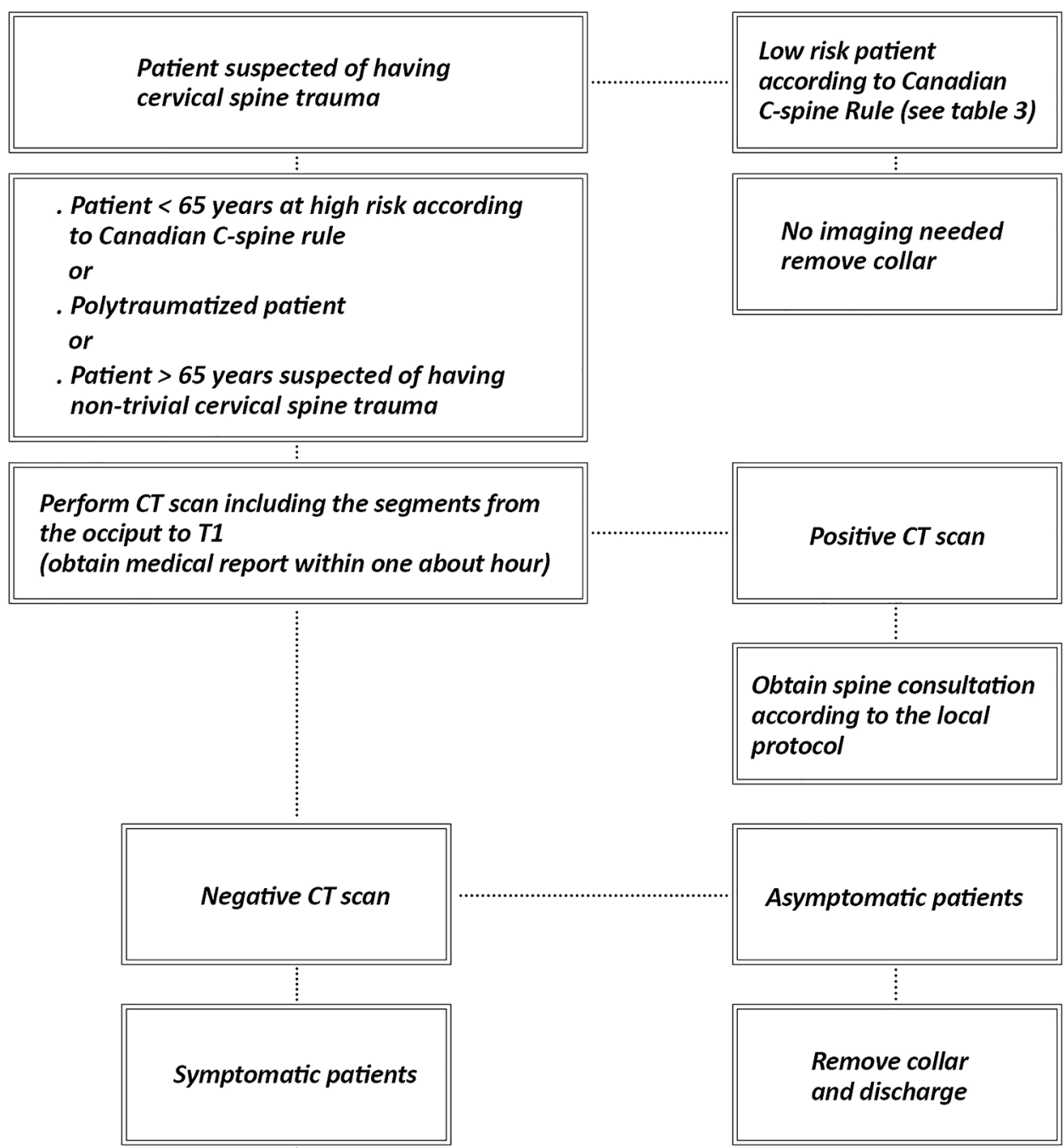

. Spine consultation

or

. Further diagnostic evaluation

or

. Observation according to clinical judgement 
Table 3 Normalized citations for each guideline

\begin{tabular}{|c|c|c|c|}
\hline Guidelines & Website/Journal & Grading recommendation system & Search strategy \\
\hline EAST 2009 & $\begin{array}{l}\text { The Journal of TRAUMA }{ }^{\circledR} \text { Injury, } \\
\text { Infection, and Critical Care }\end{array}$ & $\begin{array}{l}\text { Articles were classified as Class I, II, or } \\
\text { III as described in the EAST primer } \\
\text { on evidence-based medicine as fol- } \\
\text { lows: Class I: Prospective, randomized } \\
\text { clinical trials (no references) } \\
\text { Class II: Clinical studies in which } \\
\text { data were collected prospectively or } \\
\text { retrospective analyses based on clearly } \\
\text { reliable data ( } 20 \text { references) } \\
\text { Class III: Studies based on retrospec- } \\
\text { tively collected data ( } 32 \text { references). } \\
\text { Recommendations were classified } \\
\text { as levels } 1,2 \text {, or } 3 \text { according to the } \\
\text { following definitions: Level } 1: \text { The } \\
\text { recommendation is convincingly justi- } \\
\text { fiable based on the available scientific } \\
\text { information alone. This recommenda- } \\
\text { tion is usually based on class I data; } \\
\text { however, strong class II evidence may }\end{array}$ & $\begin{array}{l}\text { A search of the National Library of } \\
\text { Medicine and the National Institutes } \\
\text { of Health MEDLINE database was } \\
\text { performed using PubMed (http://www. } \\
\text { pubmed.gov). The search retrieved } \\
\text { English language articles regarding } \\
\text { the identification of CS injury from } \\
1998 \text { to 2007; review articles, letters } \\
\text { to the editor, editorials, other items } \\
\text { of general commentary, and case } \\
\text { reports were excluded from the search. } \\
\text { These articles were then reviewed for } \\
\text { relevance by the committee chair, and } \\
\text { the final reference list of } 78 \text { citations } \\
\text { was distributed to the remainder of the } \\
\text { study group for review. Of these, } 52 \\
\text { were felt to be useful for construction } \\
\text { of these guidelines, and an evidentiary } \\
\text { table was constructed }\end{array}$ \\
\hline
\end{tabular}

AANS/CNS 2013 Clinical Neurosurgery form the basis for a level 1 recommendation, especially if the issue does not lend itself to testing in a randomized format. Conversely, low quality or contradictory class I data may not be able to support a level 1 recommendation

Level 2: The recommendation is reasonably justifiable by available scientific evidence and strongly supported by expert opinion. This recommendation is usually supported by class II data or a preponderance of class III evidence Level 3: The recommendation is supported by available data, but adequate scientific evidence is lacking. This recommendation is generally supported by class III data. This type of recommendation is useful for educational purposes and in guiding future clinical research

Different from previous recommendations, the levels that used to be called standards, guidelines, and options are now referred to as Level I, Level II, and Level III, bringing them more in line with other neurosurgical and medical specialty paradigms and allowing the use of the term guidelines to denote the broader scope of the overall recommendations

In accordance with the established practice of guideline development within organized neurosurgery, a thorough review of the medical literature was undertaken for each subject chosen for evaluation. Although literature outside the English language was excluded, a sample of non-English abstracts that could be found in the database of the National Library of Medicine failed to reveal any data significantly different from what we found in the English literature. Each chapter of recommendations contained in the new guidelines uses standard search techniques fully described in each chapter

After articles appropriate to each review question were identified, a rigorous critical evaluation was undertaken to establish the strength (quality) of the evidence and the level (certainty) of the recommendations 
Table 3 (continued)

\begin{tabular}{lll} 
Guidelines $\quad$ Website/Journal Grading recommendation system \\
\hline
\end{tabular}

NICE 2016 https://www.nice.org.uk/guidance/ng41 GRADE
to the parameters stipulated within

the NICE Guidelines Manual [2012].

Databases were searched using

medical subject headings and free-text terms. Foreign language studies were not reviewed and, where possible, searches were restricted to articles published in the English language. All searches were conducted in MED-

LINE, Embase, and the Cochrane Library, and were updated for the final time on 27th March 2015. No papers added to the databases after this date were considered

Search strategies were quality assured by cross-checking reference lists of highly relevant papers, analysing search strategies in other systematic reviews, and asking GDG members to highlight any additional studies. The questions, the study types applied, the databases searched and the years covered can be found in Appendix F. The titles and abstracts of records retrieved by the searches were sifted for relevance, with potentially significant publications obtained in full text. These were then assessed against the inclusion criteria 


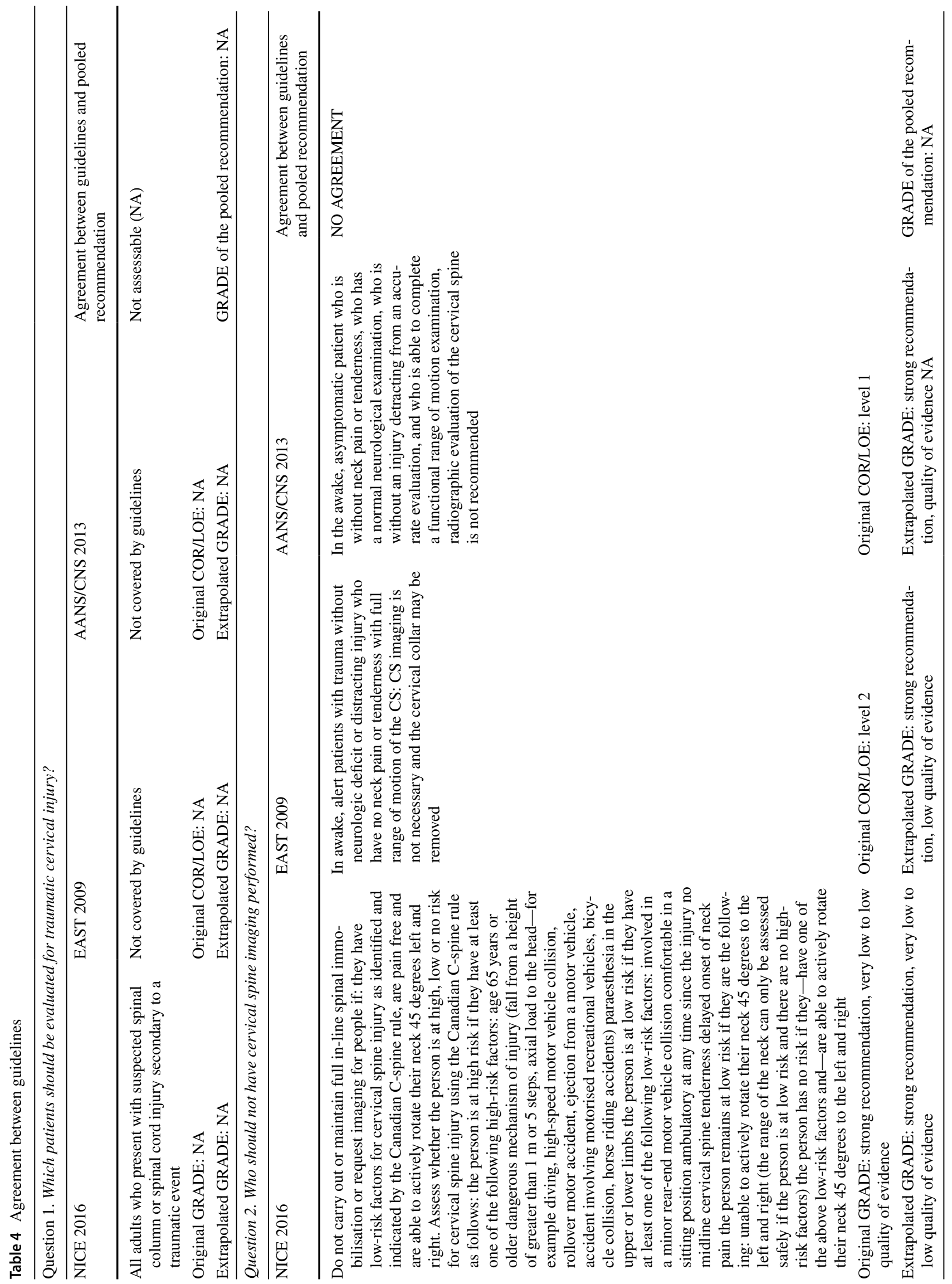




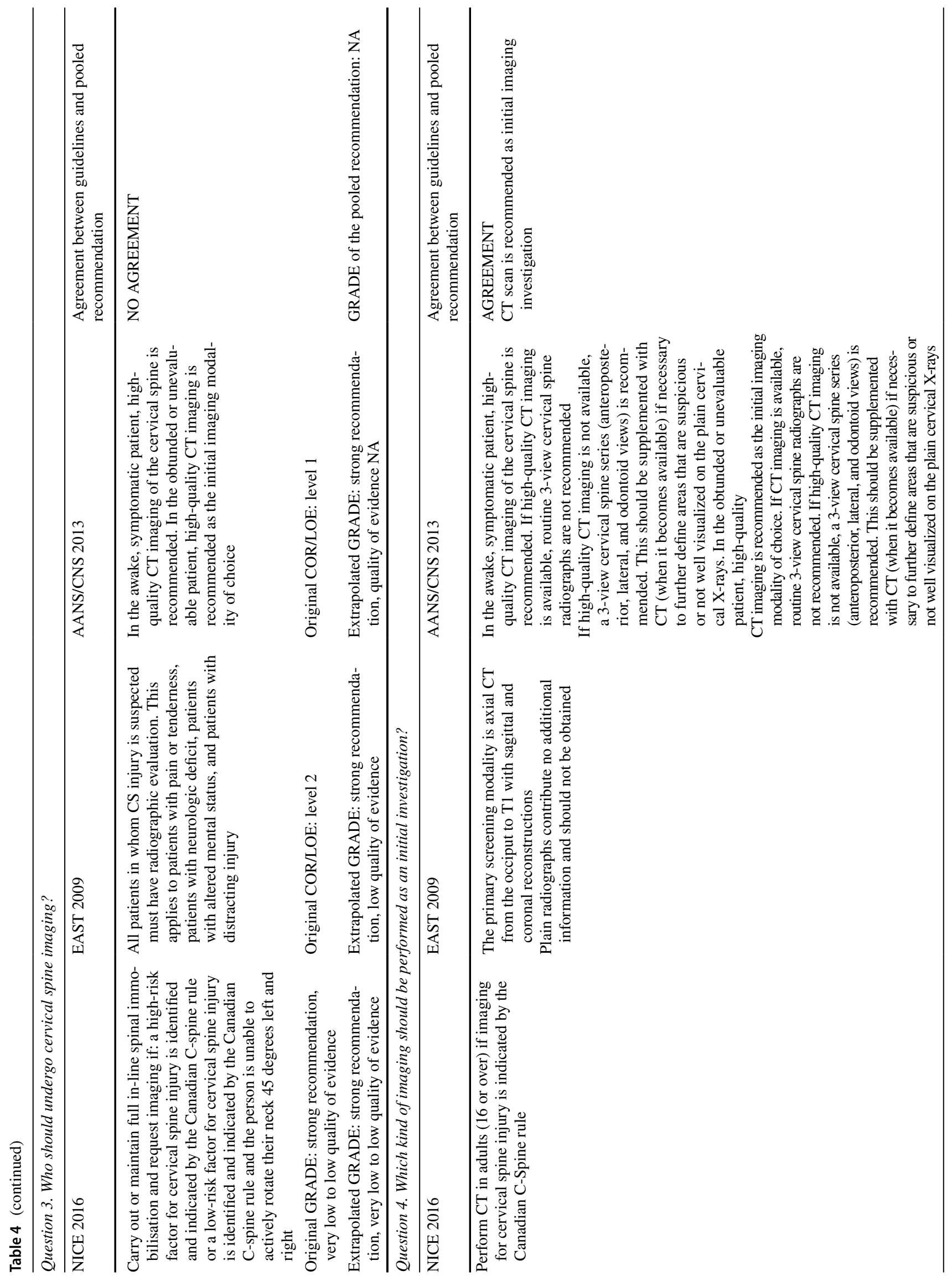




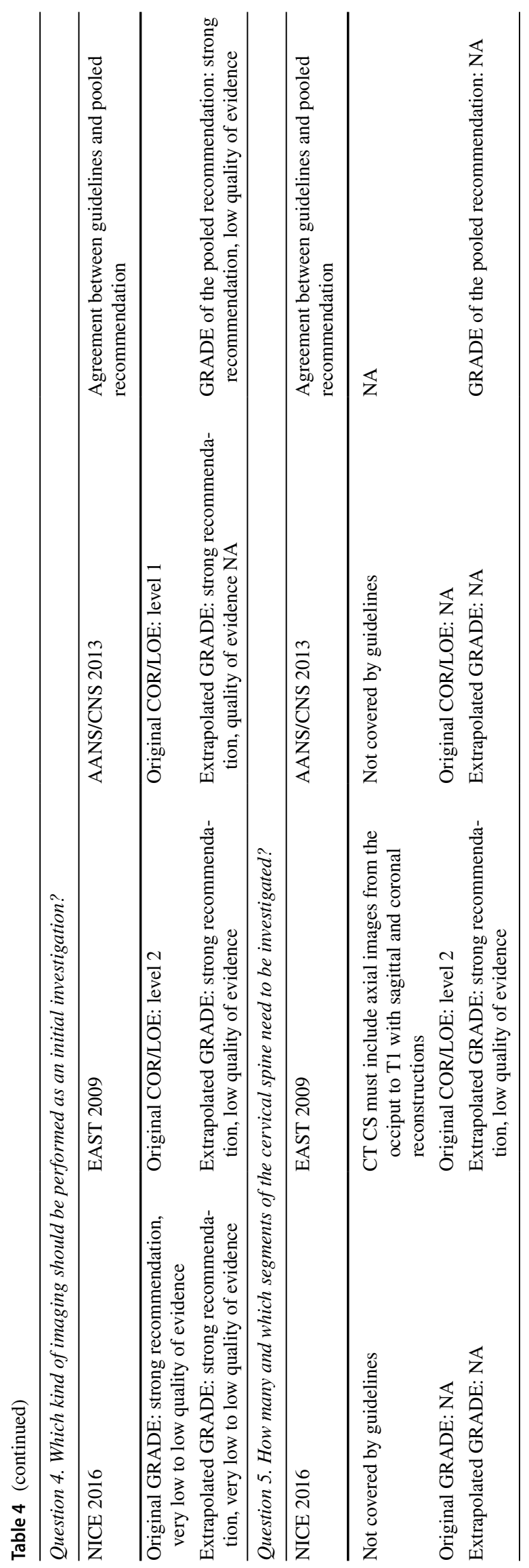


Table 5 References for each guideline

Question 1: Which kind of patients should be evaluated for traumatic cervical injury?

\begin{tabular}{lll}
\hline NICE 2016 & EAST 2009 & AANS/CNS 2013 \\
\hline Page: 17 & Page: NA & Page: NA \\
References: NA & References: NA & References: NA
\end{tabular}

Question 2. Who should not have cervical spine imaging performed?

\begin{tabular}{lll}
\hline NICE 2016 & EAST 2009 & AANS/CNS 2013 \\
\hline Page: 72,73 & Page: 654 & Page: 83 \\
References: NA & References & References: NA
\end{tabular}

Bachulis BL, Long WB, Hynes JD, Johnson MC. Clinical indications for cervical spine radiographs in the traumatized patient. Am J Surg. 1987; 153:473-478

Ersoy G, Karcioglu O, Enginbas Y, Eray O, Ayrik C. Are cervical spine X-rays mandatory in all blunt trauma patients? Eur J Emerg Med. 1995;2:191-195

Fischer RP. Cervical radiographic evaluation of alert patients following blunt trauma. Ann Emerg Med. 1984;13:905-907

Hoffman JR, Schriger DL, Mower WR, Luo JS, Zucker M. Low-risk criteria for cervical spine radiography in blunt trauma: a prospective study. Ann Emerg Med. 1992;12:1454-1460

Kreipke DL, Gillespie KR, McCarthy MC, Mail JT, Lappas JC, Broadie TA. Reliability of indications for cervical spine films in trauma patients. J Trauma. 1989;29:1438-1439

Lindsey RW, Diliberti TC, Doherty BJ, Watson AB. Efficacy of radiographic evaluation of the cervical spine in emergency situations. South Med J. 1993;86:1253-1255

Neifeld GL, Keene JG, Hevesy G, Leikin J, Proust A, Thisted RA. Cervical injury in head trauma. J Emerg Med. 1988;6:203-207

Roberge RJ, Wears RC, Kelly M, et al. Selective application of cervical spine radiography in alert victims of blunt trauma: a prospective study. J Trauma. 1988;28:784-788

Roth BJ, Martin RR, Foley K, Barcia PJ, Kennedy P. Roentgenographic evaluation of the cervical spine. A selective approach. Arch Surg. 1994;129:643-645

Saddison D, Vanek VW, Racanelli JL. Clinical indications for Cervical spine radiographs in alert trauma patients. Am Surg. 1991; 57:366-369

Velmahos GC, Theodorou D, Tatevossian R, et al. Radiographic cervical spine evaluation in the alert asymptomatic blunt trauma victim: much ado about nothing. J Trauma. 1996;40:768-774

Gonzales RP, Fried PO, Bukhalo M, Holevar MR, Falimirski ME. Roleof clinical examination in screening for blunt cervical spine injury. J Am Coll Surg. 1999;189:152-157

Hoffman JR, Mower WR, Wolfson AB, Todd KH, Zucker MI. Validation of a set of clinical criteria to rule out injury to the cervical spine in patients with blunt trauma. N Engl J Med. 2000;343:94-99

Stiell IG, Clement CM, McKnight RD, et al. The Canadian C-spine rule versus the NEXUS low-risk criteria in patients with trauma. N Engl J Med. 2003;349:2510-2518

Duane TM, Dechert T, Wolfe LG, Aboutanos MB, Malhotra AK, Ivatury RR. Clinical examination and its reliability in identifying cervical spine fractures. J Trauma. 2007;62:1405-1410

Question 3. Who should undergo cervical spine imaging?

\begin{tabular}{lll}
\hline NICE 2016 & EAST 2009 & AANS/CNS 2013 \\
\hline Page: 73,74 & Page: 654 & Page: 84, 85 \\
References: NA & References: NA & References: NA \\
\hline
\end{tabular}

Question 6. Within what timeframe should the imaging report be received?

\begin{tabular}{llll}
\hline NICE 2016 & EAST 2009 & AANS/CNS 2013 & $\begin{array}{c}\text { Agreement between guidelines and } \\
\text { pooled recommendation }\end{array}$ \\
\hline $\begin{array}{l}\text { Imaging for spinal injury should } \\
\text { be performed urgently, and the }\end{array}$ & Not covered by guidelines & Not covered by guidelines & NA \\
$\begin{array}{l}\text { images should be interpreted } \\
\text { immediately by a healthcare } \\
\text { professional with training and } \\
\text { skills in this area }\end{array}$ & & \\
\hline
\end{tabular}


Table 5 (continued)

Question 7. When should the cervical collar be removed?

\begin{tabular}{lll}
\hline NICE 2016 & EAST 2009 & AANS/CNS 2013 \\
\hline Page: 73 & Page: 654 & Page: 83, 83 \\
References: NA & References & References: NA
\end{tabular}

Ackland HM, Cooper JD, Malham GM, Kossmann T. Factors predicting cervical collar-related decubitus ulceration in major trauma patients. Spine. 2007;32:423-428

Chendrasekhar A, Moorman DW, Timberlake GA. An evaluation of the effects of semirigid cervical collars in patients with severe closed head

injury. Am Surg. 1998;64:604-606

Powers J, Daniels D, McGuire C, Hilbish C. The incidence of skin breakdown associated with the use of cervical collars. J Trauma Nurs. 2006;13:198-200

Hunt K, Hallworth S, Smith M. The effects of rigid collar placement on intracranial and cerebral perfusion pressures. Anaesthesia. 2001;56:511-513

Mobbs RJ, Stoodley MA, Fuller J. Effect of cervical hard collar on intracranial injury after head injury. ANZ J Surg. 2002;72:389-391

Stelfox HT, Velmahos GC, Gettings E, Bigatello LM, Schmidt U. Computed tomography for early and safe discontinuation of cervical spine immobilization in obtunded multiply injured patients. $\mathbf{J}$ Trauma. 2007;63:630-636.14. Bachulis BL, Long WB, Hynes JD, Johnson MC. Clinical indications for cervical spine radiographs in the traumatized patient. Am J Surg. 1987;153:473-478

Ersoy G, Karcioglu O, Enginbas Y, Eray O, Ayrik C. Are cervical spine X-rays mandatory in all blunt trauma patients? Eur J Emerg Med. 1995;2:191-195

Fischer RP. Cervical radiographic evaluation of alert patients following blunt trauma. Ann Emerg Med. 1984;13:905-907

Hoffman JR, Schriger DL, Mower WR, Luo JS, Zucker M. Low-risk criteria for cervical spine radiography in blunt trauma: a prospective study. Ann Emerg Med. 1992;12:1454-1460

Kreipke DL, Gillespie KR, McCarthy MC, Mail JT, Lappas JC, Broadie TA. Reliability of indications for cervical spine films in trauma patients. J Trauma. 1989;29:1438-1439

Lindsey RW, Diliberti TC, Doherty BJ, Watson AB. Efficacy of radiographic evaluation of the cervical spine in emergency situations. South Med J. 1993;86:1253-1255

Neifeld GL, Keene JG, Hevesy G, Leikin J, Proust A, Thisted RA Cervical injury in head trauma. J Emerg Med. 1988;6:203-207

Roberge RJ, Wears RC, Kelly M, et al. Selective application of cervical spine radiography in alert victims of blunt trauma: a prospective study. J Trauma. 1988;28:784-788

Roth BJ, Martin RR, Foley K, Barcia PJ, Kennedy P. Roentgenographic evaluation of the cervical spine. A selective approach. Arch Surg. 1994;129:643-645

Saddison D, Vanek VW, Racanelli JL. Clinical indications for cervical spine radiographs in alert trauma patients. Am Surg. 1991; 57:366-369

Velmahos GC, Theodorou D, Tatevossian R, et al. Radiographic cervical spine evaluation in the alert asymptomatic blunt trauma victim: much ado about nothing. J Trauma. 1996;40:768-774

Gonzales RP, Fried PO, Bukhalo M, Holevar MR, Falimirski ME. Role of clinical examination in screening for blunt cervical spine injury. J Am Coll Surg. 1999;189:152-157

Hoffman JR, Mower WR, Wolfson AB, Todd KH, Zucker MI. Validation of a set of clinical criteria to rule out injury to the cervical spine in patients with blunt trauma. N Engl J Med. 2000;343:94-99

Stiell IG, Clement CM, McKnight RD, et al. The Canadian C-spine rule versus the NEXUS low-risk criteria in patients with trauma. N Engl J Med. 2003;349:2510-2518

Schuster R, Waxman K, Sanchez B, et al. Magnetic resonance imaging is not needed to clear cervical spines in blunt trauma patients with normal computed tomographic results and no motor deficits. Arch Surg. 2005;140:762-766

Fazl M, LaFebvre J, Willinsky RA, Gertzbein S. Posttraumatic ligamentous disruption of the cervical spine, an easily overlooked diagnosis: presentation of three cases. Neurosurgery. 1990;26:764-678

Ficker R, Gachter A. Lateral flexion/extension radiographs: still recommended following cervical spine injury. Arch Orthop Trauma Surg 1994;113:115-116

Lewis LM, Docherty M, Ruoff BE, Fortney JP, Keltner RA Jr, Britton P. Flexion-extension views in the evaluation of cervical spine injuries. Ann Emerg Med. 1991;20:117-121

Brady WJ, Moghtader J, Cutcher D, Exline C, Young J. ED use of flexion-extension cervical spine radiography in the evaluation of blunt trauma. Am J Emerg Med. 1999;17:504-508

Insko EK, Gracias VH, Gupta R, Goettler CE, Gaieski DF, Dalinka MK. Utility of flexion and extension radiographs of the cervical spine in the acute evaluation of blunt trauma. J Trauma. 2002;53:426-429

Pollack CV Jr, Hendey GW, Martin DR, Hoffman JR, Mower WR; NEXUS Group. Use of flexionextension radiographs of the cervical spine in blunt trauma. Ann Emerg Med. 2001;38:8-11 
Table 5 (continued)

Question 4. Which kind of imaging should be performed as an initial investigation?

\begin{tabular}{lll}
\hline NICE 2016 & EAST 2009 & AANS/CNS 2013
\end{tabular}

Page: 148

References: NA
Page: 654

References

Berne JD, Velmahos GC, El-Tawil Q, et al. Value of complete cervical helical computed tomographic scanning in identifying cervical spine

injury in the unevaluable blunt trauma patient with multiple injuries: a prospective study. J Trauma. 1999;47:896-903

Griffen MM, Frykberg ER, Kerwin AJ, et al. Radiographic clearance of blunt cervical spine injury: plain radiograph or computed tomography scan? J Trauma. 2003;55:222-227

Diaz JJ, Gillman C, Morris JA Jr, May AK, Carrillo YM, Guy J. Are five-view plain films of the cervical spine unreliable? A prospective evaluation in blunt trauma patients with altered mental status. J Trauma 2003;55:658-664

Brohi K, Healy M, Fotheringham T, et al. Helical computed tomographic scanning for the evaluation of the cervical spine in the unconscious, intubated trauma patient. J Trauma. 2005;58:897-901

Mathen R, Inaba K, Munera F, et al. Prospective evaluation of multislice computed tomography versus plain radiographic cervical spine clearance in trauma patients. J Trauma. 2007;62:1427-1431

Holmes JF, Akkinepalli R. Computed tomography versus plain radiography to screen for cervical spine injury: a meta-analysis. J Trauma. 2005;58:902-905

Barba CA, Taggert J, Morgan AS, et al. A new cervical spine clearance protocol using computed tomography. J Trauma. 2001;51:652-657

Brown CV, Antevil JL, Sise MJ, Sack DI. Spiral computed tomography for the diagnosis of cervical, thoracic, and lumbar spine fractures: its time has come. J Trauma. 2005;58:890-896

Rabb CH, Johnson JL, VanSickle D, Beauchamp K, Bolles G, Moore EE. Are upright lateral cervical radiographs in the obtunded trauma patient useful? A retrospective study. World J Emerg Surg. 2007;2:4

Sanchez B, Waxman K, Jones T, Conner S, Chung R, Becerra S Cervical spine clearance in blunt trauma: evaluation of a computed tomography-based protocol. J Trauma. 2005;59:179-183

Schenarts PJ, Diaz J, Kaiser C, Carrillo Y, Eddy V, Morris JA Jr Prospective comparison of admission computed tomographic scan and plain films of the upper cervical spine in trauma patients with altered mental status. J Trauma. 2001;51:663-669

Widder S, Doig C, Burrowes P, Larsen G, Hurlbert RJ, Kortbeek JB. Prospective evaluation of computed tomographic scanning for the spinal clearance of obtunded trauma patients: preliminary results. J Trauma. 2004;56:1179-1184

Daffner RH. Cervical radiography for trauma patients: a time effective technique? AJR Am J Roentgenol. 2000;175:1309-1311

Daffner RH. Helical CT of the cervical spine for trauma patients: a time study. AJR Am J Roentgenol. 2001;177:677-679

Blackmore CC, Ramsey SD, Mann FA, Deyo RA. Cervical spine screening with CT in trauma patients: a cost-effectiveness analysis. Radiology. 1999;212:117-125

Question 5. How many and which segments of the cervical spine need to be investigated?

\begin{tabular}{|c|c|c|}
\hline NICE 2016 & EAST 2009 & AANS/CNS 2013 \\
\hline Page: NA & Page:654 & Page: NA \\
\hline References: NA & References: NA & References: NA \\
\hline \multicolumn{3}{|c|}{ Question 6. Within what timeframe should the imaging report be received? } \\
\hline NICE 2016 & EAST 2009 & AANS/CNS 2013 \\
\hline Page: 147 & Page: NA & Page: NA \\
\hline References: NA & References: NA & References: NA \\
\hline
\end{tabular}


Question 6. Within what timeframe should the imaging report be received?

\begin{tabular}{|c|c|c|c|c|}
\hline \multicolumn{2}{|l|}{ NICE 2016} & EAST 2009 & AANS/CNS 2013 & $\begin{array}{l}\text { Agreement between guidelines and } \\
\text { pooled recommendation }\end{array}$ \\
\hline \multicolumn{2}{|c|}{$\begin{array}{l}\text { Original GRADE: weak recom- } \\
\text { mendation, very low to low } \\
\text { quality of evidence }\end{array}$} & Original COR/LOE: NA & Original COR/LOE: NA & \\
\hline \multicolumn{2}{|c|}{$\begin{array}{l}\text { Extrapolated GRADE: weak rec- } \\
\text { ommendation, very low to low } \\
\text { quality of evidence }\end{array}$} & Extrapolated GRADE: NA & Extrapolated GRADE: NA & $\begin{array}{l}\text { GRADE of the pooled recommen- } \\
\text { dation: NA }\end{array}$ \\
\hline \multicolumn{5}{|c|}{ Question 7. When should the cervical collar be removed? } \\
\hline NICE 2016 & EAST 200 & & $\mathrm{ANS} / \mathrm{CNS}$ & $\begin{array}{l}\text { Agreement between guidelines and } \\
\text { pooled recommendation }\end{array}$ \\
\hline $\begin{array}{l}\text { Do not carry out } \\
\text { or maintain full } \\
\text { in-line spinal } \\
\text { immobilisation or } \\
\text { request imaging } \\
\text { for people if: they } \\
\text { have low-risk } \\
\text { factors for cervi- } \\
\text { cal spine injury } \\
\text { as identified and } \\
\text { indicated by the } \\
\text { Canadian C-spine } \\
\text { rule, are pain free } \\
\text { and are able to } \\
\text { actively rotate } \\
\text { their neck } 45 \\
\text { degrees left and } \\
\text { right }\end{array}$ & \multicolumn{2}{|c|}{$\begin{array}{l}\text { Cervical collar should be removed as } \\
\text { soon as feasible after trauma. (level 3) } \\
\text { In awake, alert patients with trauma } \\
\text { without neurologic deficit or distract- } \\
\text { ing injury who have no neck pain or } \\
\text { tenderness with full range of motion } \\
\text { of the CS imaging is not necessary and } \\
\text { the cervical collar may be removed. } \\
\text { (level2) } \\
\text { For the neurologically intact awake and } \\
\text { alert patient complaining of neck pain } \\
\text { with a negative CT: } \\
\text { A. Continue cervical collar } \\
\text { B. Cervical collar may be removed after } \\
\text { negative MRI (level 3) } \\
\text { C. Cervical collar may be removed after } \\
\text { negative and adequate F/E films (level } \\
\text { 3) } \\
\text { For the obtunded patient with a negative } \\
\text { CT and gross motor function of all } \\
\text { four extremities the risk/benefit ratio of } \\
\text { obtaining MRI in addition to CT is not } \\
\text { clear, and its use must be individual- } \\
\text { ized in each } \\
\text { institution (level 3). Options are as fol- } \\
\text { lows: } \\
\text { A. Continue cervical collar immobiliza- } \\
\text { tion until a clinical } \\
\text { examination can be performed } \\
\text { B. Remove the cervical collar on the } \\
\text { basis of CT alone } \\
\text { C. Obtain MRI } \\
\text { If MRI disclosed nothing abnormal, the } \\
\text { cervical collar may be safely removed } \\
\text { (level 2) }\end{array}$} & $\begin{array}{l}\text { In the awake, asymptomatic patient } \\
\text { who is without neck pain or tender- } \\
\text { ness, who has a normal neurologi- } \\
\text { cal examination, who is without an } \\
\text { injury detracting from an accurate } \\
\text { evaluation, and who is able to com- } \\
\text { plete a functional range of motion } \\
\text { examination, radiographic evalu- } \\
\text { ation of the cervical spine is not } \\
\text { recommended. Discontinuance of } \\
\text { cervical immobilization for these } \\
\text { patients is recommended without } \\
\text { cervical spinal imaging } \\
\text { In the awake patient with neck pain } \\
\text { or tenderness and normal high- } \\
\text { quality CT imaging or normal } \\
3 \text {-view cervical spine series (with } \\
\text { supplemental CT if indicated), the } \\
\text { following recommendations should } \\
\text { be considered: } \\
\text { (1) Continue cervical immobiliza- } \\
\text { tion until } \\
\text { asymptomatic; } \\
\text { (2) Discontinue cervical immobiliza- } \\
\text { tion after normal } \\
\text { and adequate dynamic flexion/exten- } \\
\text { sion radiographs; } \\
\text { (3) Discontinue cervical immobiliza- } \\
\text { tion after a normal } \\
\text { MRI obtained within } 48 \mathrm{~h} \text { of injury } \\
\text { (4) Discontinue cervical immobiliza- } \\
\text { tion at the discretion of the treating } \\
\text { physician }\end{array}$ & $\begin{array}{l}\text { PARTIAL AGREEMENT } \\
\text { Cervical collar should be removed in } \\
\text { awake, alert, asymptomatic patient } \\
\text { without neurologic deficit, without } \\
\text { neck pain or tenderness, without } \\
\text { distracting injury, who is able to } \\
\text { complete a functional range of motion } \\
\text { examination (EAST; AANS/CNS) and } \\
\text { who have low-risk factors for cervical } \\
\text { spine injury as identified by the Cana- } \\
\text { dian C-spine rule (NICE-see NICE } \\
\text { recommendation) } \\
\text { In the awake symptomatic patient with a } \\
\text { negative CT scan consider: } \\
\text { Continue cervical collar until asympto- } \\
\text { matic (EAST, AANS/CNS) } \\
\text { Remove cervical collar after a negative } \\
\text { MRI (EAST, AANS/CNS) } \\
\text { Remove cervical collar after adequate } \\
\text { flexion-extension X-ray (EAST, } \\
\text { AANS/CNS) } \\
\text { Discontinue cervical immobilization at } \\
\text { the discretion of the treating physician } \\
\text { (AANS/CNS) } \\
\text { For the obtunded patient with a negative } \\
\text { CT and gross motor function of all } \\
\text { four extremities: } \\
\text { Continue cervical collar immobiliza- } \\
\text { tion until a clinical examination can be } \\
\text { performed } \\
\text { Remove the cervical collar on the basis } \\
\text { of CT alone } \\
\text { Obtain MRI } \\
\text { If MRI disclosed nothing abnormal, the } \\
\text { cervical collar may be safely removed } \\
\text { (EAST) }\end{array}$ \\
\hline
\end{tabular}

\begin{tabular}{lc}
\hline $\begin{array}{c}\text { Original GRADE: } \\
\text { strong recommen- } \\
\text { dation, very low } \\
\text { to low quality of } \\
\text { evidence }\end{array}$ & $\begin{array}{c}\text { Original COR/LOE: (see in the text } \\
\text { level 3, level 2, level 2, level 3, level 3, }\end{array}$ \\
$\begin{array}{l}\text { Extrapolated } \\
\text { GRADE: strong }\end{array}$ & $\begin{array}{c}\text { Extrapolated GRADE: Level 2 here } \\
\text { evaluated as follows: "strong recom- } \\
\text { recommenda- } \\
\text { mendation, low quality of evidence" }\end{array}$ \\
$\begin{array}{c}\text { tion, very low to } \\
\text { low quality of }\end{array}$ & $\begin{array}{c}\text { Level 3 here evaluated as "weak recom- } \\
\text { mendation, low quality of evidence" }\end{array}$
\end{tabular}

Original COR/LOE: level 1; level 3 (EAST)

Extrapolated GRADE: strong recommendation, quality of evidence NA; weak recommendation, quality of evidence NA
GRADE of the pooled recommendation: NA 
Funding Open access funding provided by Università degli Studi di Milano within the CRUI-CARE Agreement. This research did not receive any specific grant from fundingagencies in the public, commercial, or not-for-profit sectors.

\section{Declarations}

Conflict of interest The authors declare that they have no conflict of interest.

Statement of human and animal rights This article does not contain any studies with human participants or animals performed by any of the authors.

Informed consent For this type of study formal consent is not required.

Open Access This article is licensed under a Creative Commons Attribution 4.0 International License, which permits use, sharing, adaptation, distribution and reproduction in any medium or format, as long as you give appropriate credit to the original author(s) and the source, provide a link to the Creative Commons licence, and indicate if changes were made. The images or other third party material in this article are included in the article's Creative Commons licence, unless indicated otherwise in a credit line to the material. If material is not included in the article's Creative Commons licence and your intended use is not permitted by statutory regulation or exceeds the permitted use, you will need to obtain permission directly from the copyright holder. To view a copy of this licence, visit http://creativecommons.org/licenses/by/4.0/.

\section{References}

1. https://www.sci-info-pages.com/spinal-cord-injury-facts-and-stati stics (2018). Accessed 25 Jan 2021

2. Ham WH, Schoonhoven L, Schuurmans MJ et al (2016) Pressure ulcers, indentation marks and pain from cervical spine immobilization with extrication collars and headblocks: an observational study. Injury 47(9):1924-1931

3. Costantino G, Podda GM, Falsetti L et al (2017) Guidelines on the management of atrial fibrillation in the emergency department: a critical appraisal. Intern Emerg Med 12:693-703

4. http://gdt.guidelinedevelopment.org/app/handbook/handbook. html (2013). Accessed 25 Jan 2021

5. Andrews JC, Schünemann HJ, Oxman AD et al (2013) GRADE guidelines: 15. Going from evidence to recommendation-determinants of a recommendation's direction and strength. J Clin Epidemiol 66:726-735

6. https://www.nice.org.uk/guidance/ng41 (2016). Accessed 25 Jan 2021
7. Como JJ, Diaz JJ, Dunham CM et al (2009) Practice management guidelines for identification of cervical spine injuries following trauma: update from the eastern association for the surgery of trauma practice management guidelines committee. J Trauma 67(3):651-659

8. Walters BC, Hadley MN, Hurlbert RJ et al (2013) Guidelines for the management of acute cervical spine and spinal cord injuries: 2013 update. Neurosurgery 60(CN_suppl_1):82-91

9. National Emergency X-Radiography Utilization Study Group, Hoffman JR, Mower WR, Wolfson AB et al (2000) Validity of a set of clinical criteria to rule out injury to the cervical spine in patients with blunt trauma. N Engl J Med 343(2):94-99 ((Erratum in: N Engl J Med 2001 Feb 8;344(6):464))

10. Stiell IG, Wells GA, Vandemheen KL et al (2001) The Canadian $\mathrm{C}$-spine rule for radiography in alert and stable trauma patients. JAMA 286(15):1841-1848

11. Michaleff ZA, Maher CG, Verhagen AP et al (2012) Accuracy of the Canadian C-spine rule and NEXUS to screen for clinically important cervical spine injury in patients following blunt trauma: a systematic review. CMAJ 184(16):E867-E876

12. Moser N, Lemeunier N, Southerst D et al (2018) Validity and reliability of clinical prediction rules used to screen for cervical spine injury in alert low-risk patients with blunt trauma to the neck: part 2. A systematic review from the Cervical Assessment and Diagnosis Research Evaluation (CADRE) Collaboration. Eur Spine J 27(6):1219-1233

13. Stiell IG, Clement CM, McKnight RD et al (2003) The Canadian $\mathrm{C}$-spine rule versus the NEXUS low- risk criteria in patients with trauma. N Engl J Med 349(26):2510-2518

14. Bandiera G, Stiell IG, Wells GA et al (2003) The Canadian C-spine rule performs better than unstructured physician judgment. Ann Emerg Med 42(3):395-402

15. Crim JR, Moore K, Brodke D (2001) Clearance of the cervical spine in multitrauma patients: the role of advanced imaging. Semin Ultrasound CT MR 22(4):283

16. Expert Panel on Neurological Imaging and Musculoskeletal Imaging, Beckmann NM, West OC, Nunez DJ (2019) ACR appropriateness criteria ${ }^{\circledR}$ suspected spine trauma. J Am Coll Radiol 16(5S):S264-S285

17. Saltzherr TP, Fung Kon Jin PHP, Beenen LF et al (2009) Diagnostic imaging of cervical spine injuries following blunt trauma: a review of the literature and practical guideline. Injury 40(8):795-800

18. Goergen S (2004) Imaging guideline 1: blunt cervical spine trauma. Australas Radiol 48(3):287

Publisher's Note Springer Nature remains neutral with regard to jurisdictional claims in published maps and institutional affiliations. 